\title{
Organisational Impact of Enterprise Architecture and Business Process Capability in South African Organisations
}

\author{
Charl Van Zijl and Jean-Paul Van Belle
}

\begin{abstract}
Organisations rely on information and communication technologies (ICT) as an essential part of their operations, as well as providing strategic advantage. Enterprise architecture (EA) is a function within an organisation to maximise return on investment of ICTs, and to ensure that the Information Systems (IS) function in the organisation is not a bottleneck for organisational growth and agility. This study surveyed small and large organisations in South Africa, to determine what the impact (and value) of the IS architecture and maturity of the IS function is on the business processes and the organisation as a whole. We also compared larger versus smaller organisations as well as informative-intensive versus non information-intensive organisations. The key findings were that there is a strong empirical basis for many of the claimed benefits of EA. In particular, EA seems to facilitate business process automation, more so (in our sample) than business agilty. However, EA has real organisational impacts, enabling especially long term cost reduction and enterprise agility. Also, although the higher importance and impact of EA and ICTs in information-intensive organisations was confirmed, surprisingly few significant differences were found between large and small organisations.
\end{abstract}

Index Terms-Enterprise architecture, business process capability, ICT impact, South Africa.

\section{INTRODUCTION}

The effective use of information and communication technology (ICT) plays an important role in the business strategy of an organisation, be it cost reduction using efficient technology solutions, customer satisfaction through a tailored consumer experience, or competitive advantage by providing industry-leading products or services. At the same time ICTs are also fundamental in supporting general business activities and basic communication [1].

In order to stay relevant and competitive organisations need to implement ICT as an essential part of their business. Improving the use of ICT in organisations can have far reaching benefits. Because of the relatively high failure rates, against the potential benefit that effective use of ICTs can deliver, an analysis of the use of ICTs by large and SME organisations is done, with the purpose of identifying opportunities for organisations to utilize their ICT capability

Manuscript received March 13, 2014; revised June 10, 2014

C. van Zijl was with the Department of Information Systems, University of Cape Town. He is now with Santam, South Africa (e-mail: Charl.VanZijl@santam.co.za).

Jean-Paul Van Belle is with the Department of Information Systems \& Director of the Centre for IT and National Development in Africa, University of Cape Town, South Africa (e-mail: Jean-Paul.VanBelle@uct.ac.za). more effectively. The key research objectives of this research were the following:

- Does an enterprise architecture approach to ICT management bring business process benefits?

- How do the various enterprise architectural ICT sub-domains (data/information management, software application management and technology infrastructure) impact on the organisation?

- Are there differences between SMEs versus larger organisations, and information-intensive versus non-intensive organisations, in their enterprise architecture and impact factors?

These questions will be researched in a South African context using a quantitative survey approach. Hopefully the findings from this research can inform organisations with information to enable them to better leverage their current ICT investments, and to become more sustainable and competitive through adopting additional ICT deployments that fit with their organisation strategic plans. Academics researchers may be interested in the model and constructs. The rest of the paper starts with a review of relevant literature, explains the research model and methodology and details the findings.

\section{LITERATURE REVIEW}

Long term strategic ICT investment planning involves identifying and closing the gaps between the capabilities presented by the ICT of the organisation and where the organisation wants to be. We explore the role of Enterprise Architecture (EA) with regards to business Strategic Planning (SP) and the benefits EA can bring to an organisation, as well as challenges in implementing and institutionalising it in an organisation, with a focus on SMEs, defined here as having fewer than 100 to 200 employees, depending on the industry.

Enterprise architecture posits that a strategic, architectural (holistic, standardized, coordinated) approach to managing the IS function, and tighter alignment between business strategy and information system strategy results in organizational benefits (increased productivity, efficiency, agility, and maximizing returns) [2]. Enterprise Architecture approaches technology as a strategic, rather than just tactical concern [3]. TOGAF defines the purpose of enterprise architecture is "to optimize across the enterprise the often fragmented legacy of processes (both manual and automated) into an integrated environment that is responsive to change and supportive of the delivery of the business strategy." 
Enterprise Architecture can be defined as consisting of the following areas [4]:

- Business Architecture, which is concerned with defining the different business domains. It describes the organisational parts that provide a service to one or more other parts and describes the interfaces and service level agreements between those parts.

- Business Process Architecture, which is defined as a collection of interrelated tasks which solve a particular concern.

- Information Architecture, which is concerned with the use and structure of information, and alignment with organisational needs.

- Software or Application Architecture, which is concerned with the software applications, components and objects, and the relationship between them.

- Technical Architecture (shared infrastructure), which is concerned with generic technical facilities supporting many other systems.

EA focuses on the role and alignment of IS in the context of the organisational entity. Enterprise Architecture (EA) involves identifying and closing the gaps between the capabilities presented by the organisations' information systems, and where the organisation wants to be. The business strategy should inform the IS strategy, and in turn ICT capabilities should inform the business strategy. Increasing evidence of business strategies depending on ICT capabilities are observed [5].

EA can reduce duplication, and provide business with a consolidated and more accurate view of their customers. It is important that the ICT and business managers agree on the representation of the architecture, so as to facilitate common understanding. A visible (documented) EA architecture keeps management focused on the ICT resources at their disposal when creating business strategies. EA implementations driven by business requirements are more effective than those driven by technical concerns [2].

EA also creates a roadmap to leverage existing technologies and incorporate emerging technologies into the ICT landscape [5]. Organisations who build a foundation of standard technology and/or standard processes have more business agility and can respond faster to market opportunities than its competitors [6]. Since the EA of an organisation is likely to be a unique investment in ICTs, which cannot be easily copied, it provides the organisation with a competitive advantage [7]. EA also has the potential to assist in implementing industry standards, best practices, service orientated architecture, program management, knowledge management, security controls, quality management and human capital management [5].

The value of EA will only be realised when the management of an organisation incorporates it in their strategic planning methodology. Cooperation and mutual understanding of the role of business and the role of IT in crafting the strategy of the organisation is essential to successful EA benefits realisation [8]. The gap is being bridged by methodologies such as TOGAF (2009) which defines a process to produce architecture deliverables [9].

The following barriers have been identified with the institutionalization of EA in an organisation [8]:
- Organisational structure: if the organisational decision making approach leads to information asymmetry, where individual or group interests are protected at expense of the organisational interests.

- Economic Investment: the benefits of EA can be difficult to quantify in monetary value terms, which could lead to the value of EA being contested by business stakeholders.

- Administrative process: in large organisations the dispersed nature of the company as-is architecture can make it difficult for the architect to consolidate and catalogue all artefacts outside his/her immediate area, into a holistic view of the enterprise.

- Organisational Politics: because local business department managers may no longer be empowered to make key technology and related decisions, they perceive EA as a threat to their autonomy.

- Technical Capability: the success of the EA initiative may fail if architects or the organisation lacks competencies required to deploy EA.

- Business Buy-in: having a solid relationship with business managers is essential to the successful adoption of EA practice in an organisation. The artefacts produced by EA serve no purpose if not utilised. Executive support of EA initiatives is crucial.

The purpose of this study is to identify areas where an Enterprise architecture (EA) approach to ICT management can improve the use of and value derived from ICTs. A well-fitting framework that can be used to evaluate the impact that a holistic, Enterprise Architecture methodology can bring to an organisation's ICT function and/or business strategy, was recently proposed by [2]. Their research framework consists of the following areas/constructs: Information systems areas: ICT infrastructure/technology, data management and application development; the impact of the above areas on business processes; and the organisational impact. Note that their model uses formative constructs, not reflective ones.

In this study the framework will be used to look at correlations between the IS architecture capability, business processes, and organisational performance. We will also compare SMEs and large organizations to see where they differ in their technical, data and application approach.

\section{RESEARCH MethODOLOGY}

The underlying philosophy of this research is positivist as the aim of this study is to objectively examine areas were ineffiencies exist in South African organisations with regards to their ICT use, and compare large and small organisations, in order to determine in which areas an enterprise architecture approach to ICT management could bring improved value from ICTs. A survey questionnaire was used to gather information with regards to the questions stated above. A cross-sectional research timeframe was used as this survey was distributed to various South African organisations at a particular point in time.

The research sample was chosen as to represent large organisations and SMEs with a higher probability of having a complex ICT infrastructure. A purposive sampling method 
was used where industries that tend to be information intensive were selected to take part in the survey. This included book publishers, advertising agencies, data processing companies, travel agencies, estate agencies, book retail organisations, as well as non-information intensive industries such as manufacturing.

A total of 360 questionnaires were mailed by surface mail and a further 100 organisations were contacted just by electronic mail, but from these only one single response was received. A total of thirty-seven (37) responses were received. One respondent did not complete the organisational impact section of the questionnaire, but since the other sections were still useful to the research, it was included. Although resulting in a small sample size, a response rate of $10 \%$ is still considered good considering the target population.

A questionnaire was structured according to the Organizational Impact of Enterprise Architecture research framework. [2], with a few additional constructs around business process modelling and environmental factors that could influence the organisation's attitude or readiness to implement/benefit from a formal architectural approach to ICT management. As Espinosa et al. (2011) did not propose a research instrument; a questionnaire for the framework had to be designed. Eight questions were taken from [10] and 47 new test items (questions) were created using a five point Likert-type scale ranging from "Strongly Disagree" to "Strongly Agree". The questionnaire is available on simple request from the authors.

\section{DATA ANALYSIS}

This section describes the nature and results of the statistical analysis undertaken. The demographic details of the organisations are inspected and reported. A factor analysis and Cronbach alpha analysis was done to test the reliability of the model, and the necessary adjustments were made. Correlation and regression analysis was done on certain constructs in the model, and the findings presented. Finally, an analysis of the means of different variables was done, and the differences between SMEs and large as well as information-intensive and other organisations are given.

\section{A. Demographic Characteristics of Survey Sample}

The number of SMEs and large organizations that took part in the survey is tabled below (see Table I). As can be seen from the average years in operation, the sample represents organisations that have been in operation for a number of years, well past the critical stage for the development of a new business.

\begin{tabular}{cccc}
\multicolumn{4}{c}{ TABLE I: LARGE ORGANISATIONS VERSUS SMES } \\
\hline \hline $\begin{array}{c}\text { Organisation } \\
\text { category }\end{array}$ & $\begin{array}{c}\text { Number of } \\
\text { survey } \\
\text { respondents }\end{array}$ & $\begin{array}{c}\text { Average years } \\
\text { in operation }\end{array}$ & $\begin{array}{c}\text { Median of } \\
\text { years in } \\
\text { operation }\end{array}$ \\
\hline SME & 20 & 22 & 15 \\
Large & 17 & 45 & 35 \\
Total & 37 & - & - \\
\hline \hline
\end{tabular}

The industries considered for this research were banking, insurance, and other financial services, business services such as advertising, consulting, legal services, accounting services, higher education, as well as manufacturing and construction (see Table II).

TABLE II: NATURE OF BUSINESS

\begin{tabular}{lc}
\hline \multicolumn{1}{c}{ Industry } & $\begin{array}{c}\text { No of survey } \\
\text { respondents }\end{array}$ \\
\hline Manufacturing and Construction & 7 \\
Financial Services & 6 \\
Medical & 5 \\
IT Service / consulting & 4 \\
Publishing (Educational Publishing x 1, Book & 3 \\
Publishing × 1, Publishing × 1) & 2 \\
Broadcasting & 2 \\
Market Research & \\
Others (×1 each) Online Education; & $8 \times 1=8$ \\
Advertising; Fleet management; Food and & \\
Beverage; Software Distributer; Non-profit; & \\
Travel Industry; Research (S\&T) & \\
\hline \hline
\end{tabular}

The organisations were also classified as information intensive and non-information intensive organisations. For this study a non-information intensive organisation was classified one which predominantly produces information (as opposed to goods) [11]. The non-information intensive industries in this sample were mostly from the manufacturing and construction industries. There were twenty-seven (27) information intensive industries were and ten (10) non-information intensive industries.

Most (23 out of 35) respondents worked in technical management; another 6 in technical operations and only 6 were in financial or HR management (2 did not respond).

\section{B. Reliability of Model}

No prior research instrument existed for the model, so a new questionnaire had to be designed. Its validity and reliability is therefore very important. Factor analysis was used to verify if the variables (questions) load onto factors consistent with the research framework. While looking at the results of the factor analysis, the questions were considered again, and we tried to get a feel of how respondents would interpret the questions, in order to make sense of the factor loadings. In doing this came to the realization that some of the questions could be interpreted in more than one way (too broad an interpretation possible). Questions that loaded unto factors that made sense in terms of the research framework were kept, and questions that loaded together but did not relate, were only used as individual variables, and not as part of a construct.

The factor analysis (validity test) and Cronbach alpha analysis (reliability/consistency test) was done separately for each of the three major components of the research framework, in the light of the small sample. The Technology (T), Application (S) and Data (D) constructs (consisting of independent EA variables) were analyzed together, to see how the questions interrelate. Then the Business Process (B construct) questions were analysed together, and after that the Organizational Benefits / Impact (O construct) questions were analyzed, to see how these dependent variables relate. Lastly the Control variables were analyzed.

When the factor analysis of the T, D, and S constructs were done, we found a large overlap between the T, D and S 
constructs, especially the T and D, since the research model is an formative model, and the T, D and S constructs are latent constructs, with the underlying factors of $\mathrm{T}$ and $\mathrm{D}$ and $\mathrm{S}$ having an interrelationship. Given this empirical evidence, we therefore decided to re-interpret the model as a reflexive model as shown in Fig. 1.

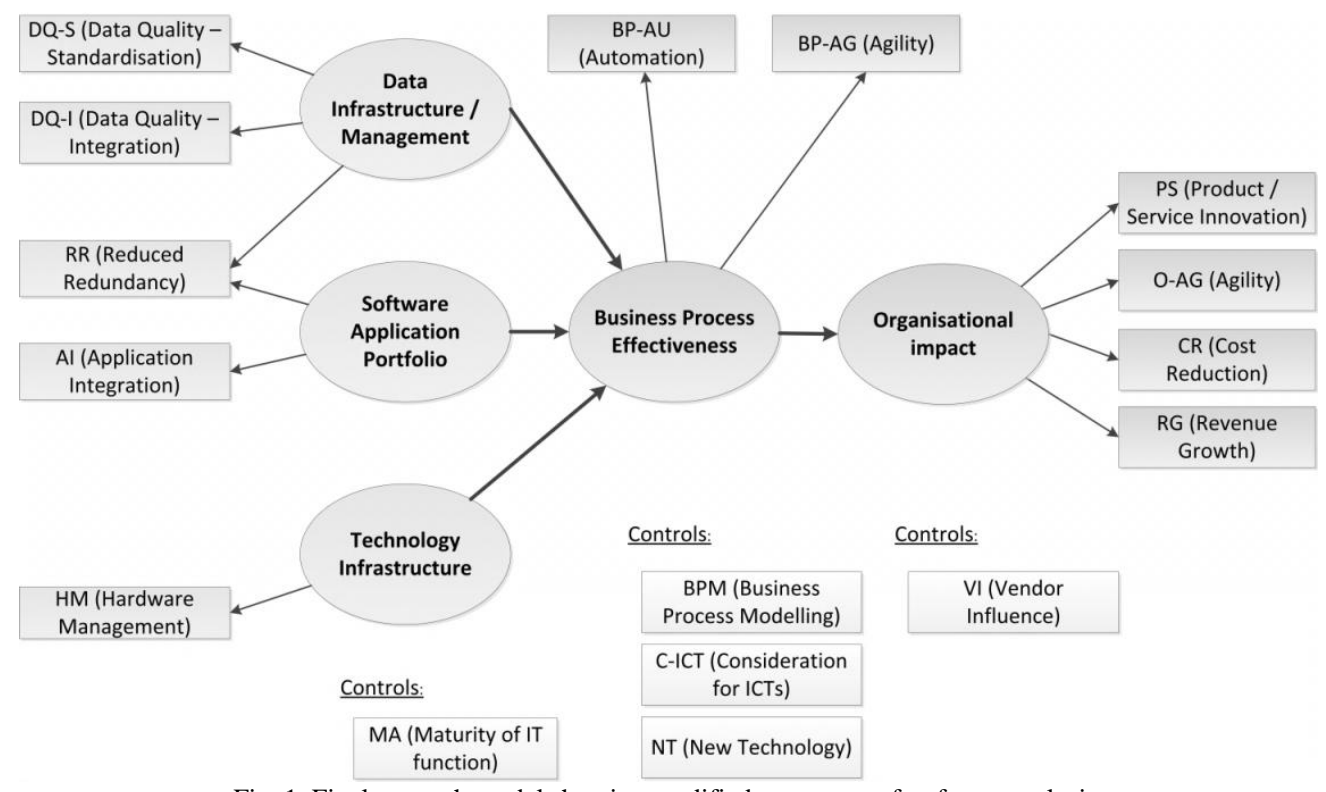

Fig. 1. Final research model showing modified constructs after factor analysis.

Note that some of the other factors also did not load cleanly and some questions (test items) were omitted; whereas in other cases slightly different conceptualisations were given for the latent model variables.

TABLE III: FINAL LIST OF CONSTRUCTS USED FOR ANALYSIS

\begin{tabular}{|c|c|c|c|}
\hline Code & $\begin{array}{l}\text { Initial construct on } \\
\text { reference model (Fig. } \\
\text { 1) }\end{array}$ & $\begin{array}{l}\text { Re-conceptualized } \\
\text { construct (name) (Fig. } \\
\text { 2) }\end{array}$ & $\begin{array}{l}\text { Cronbach } \\
\text { alpha }\end{array}$ \\
\hline DQ-S & D: Integration & $\begin{array}{l}\text { Data Quality } \\
\text { (Standardisation) }\end{array}$ & .735 \\
\hline DQ-I & $\begin{array}{l}\text { D: Redundancy, } \\
\text { Integration }\end{array}$ & $\begin{array}{l}\text { Data Quality } \\
\text { (Integration) }\end{array}$ & .699 \\
\hline HM & T: Cost, Standards & Hardware Management & .622 \\
\hline $\mathrm{RR}$ & D,S: Redundancy & $\begin{array}{l}\text { Reduced Redundancy } \\
\text { (Applications and Data) }\end{array}$ & .818 \\
\hline AI & S: Integration & $\begin{array}{l}\text { Improved Application / } \\
\text { Technical Integration }\end{array}$ & .678 \\
\hline $\begin{array}{l}\text { BP-A } \\
U\end{array}$ & $\begin{array}{l}\text { B: Automation, } \\
\text { Integration }\end{array}$ & $\begin{array}{l}\text { Increased Business } \\
\text { Process Automation }\end{array}$ & .826 \\
\hline $\begin{array}{l}\text { BP-A } \\
\text { G }\end{array}$ & $\begin{array}{l}\text { B: Redundancy, } \\
\text { Modularity }\end{array}$ & $\begin{array}{l}\text { Business Process } \\
\text { Agility }\end{array}$ & .829 \\
\hline PS & $\begin{array}{l}\text { O: Product / Service, } \\
\text { Revenue Growth }\end{array}$ & $\begin{array}{l}\text { Product / Service } \\
\text { Innovation and Value }\end{array}$ & .838 \\
\hline $\mathrm{O}-\mathrm{AG}$ & $\begin{array}{l}\text { O: Productivity, } \\
\text { Agility }\end{array}$ & Organisational Agility & .803 \\
\hline CR & O: Cost Reduction & Cost Reduction & .899 \\
\hline RG & O: Revenue Growth & Revenue Growth & .893 \\
\hline BPM & $\begin{array}{l}\text { CV: Business } \\
\text { Process Modelling }\end{array}$ & $\begin{array}{l}\text { Business Process } \\
\text { Modelling }\end{array}$ & .661 \\
\hline C-ICT & $\begin{array}{l}\text { CV: Maturity, } \\
\text { Competitor Influence }\end{array}$ & Consideration for ICTs & .828 \\
\hline VI & $\begin{array}{l}\text { CV: Vendor } \\
\text { influence }\end{array}$ & Vendor Influence & .804 \\
\hline MA & $\begin{array}{l}\text { T: Standards, D: } \\
\text { Governance, CV: } \\
\text { Governance, CV: } \\
\text { Maturity }\end{array}$ & Maturity of IT function & .810 \\
\hline NT & $\begin{array}{l}\text { CV: New } \\
\text { Technology }\end{array}$ & New Technology & .737 \\
\hline
\end{tabular}

These constructs were identified for use in correlation analysis and relationship testing. Cronbach alphas for the factors that emerged were done to ensure that the constructs are valid enough to do comparisons and correlations. The Cronbach alphas of all the constructs loaded with a factor greater than 0.6 (most exceed 0.8 ), so could be successfully used to do exploratory correlation and regression analysis (see Table III).

\section{Preliminary Analysis (Descriptive Statistics)}

Descriptive analysis was performed on all questions within each construct/area. Tabulating and comparing responses within each area, as well as evaluating their respective means, highlighted relative problem domains within each area of investigation. Given the lack of space, only the extreme values in each area are mentioned.

In the technology infrastructure area, the management of the ICT systems complexity $(\mathrm{T} 3 ; \bar{x}=2.16)$ and the infrastructural ability to enable agility (T5; $\bar{x}=3.60)$ seemed to be a particular issue (all other $\bar{x}>4.08$ ). With respect to the software application portfolio, the integration of software solutions from different vendors is a challenge ( $\mathrm{S} 3$ - this is related to the system complexity above; $\bar{x}=2.95$ ), but they appear to be successfully implemented in the end (S2; $\bar{x}=$ 3.57). This also aligns with the key challenge in the data infrastructure/information management arena, where the consolidation and integrating of data from various systems is an issue (D1; $\bar{x}=2.97, \mathrm{D} 2 ; \bar{x}=3.54)$, but nevertheless information outputs (D3; $\bar{x}=4.03$ ) are relevant for decision making.

With respect to the organisations' business processes, the integration and efficiency of business processes is an issue (B5; $\bar{x}=3.16, \mathrm{~B} 4 ; \bar{x}=$ ), but business processes are aligned with customer expectations (B6; $\bar{x}=3.70)$. However, although Business Processes Modelling (BPM) tools are not used much (M1; $\bar{x}=2.65)$, the organizations claim that they would find value in a BPM capability (M2; $\bar{x}=3.72$ ).

Finally, in terms of the organisational Impact/Benefits, the ICT systems of the organizations surveyed are not valued as 
much for contributing to market share and increased profits, but are more valued as a facilitating tool by adding value to existing products and services and ensuring smooth operation of the business function.

Among the control variables, cost considerations are seen as a limiting factor when implementing ICTs (F7; $\bar{x}=2.19$ ). Despite this, most organisations indicated that new technologies have been introduced in the organizations surveyed in the last year or are being considered (F8 \& F9; $\bar{x}$ =4.35). Most organizations monitor the performance of the organization on an on-going basis (E3; $\bar{x}=3.91)$, but perhaps not according to a formal methodology $(\mathrm{E} 1 ; \bar{x}=$ 3.17). ICTs are considered an important component of the business strategy $(\mathrm{E} 2 ; \bar{x}=3.78)$.

\section{Correlations and Regression Analysis}

Each area of the research model was analysed for variables and constructs that correlated. Significant correlations (those with correlation equal or larger than 0.5 ) between the variables are discussed below (all correlations are significant at $\mathrm{p}<.01$, except where indicated otherwise).

The model is analysed in parts; first the Business Processes variables ("D") are correlated with the IS Environment variables ("F"). Then the correlation between the Business Processes variables ("D") with the IS Capability variables ("T", "D" and " $S$ ") is investigated. Thirdly the correlation between Business Process Modelling (BPM) ("M") and IS Environment ("F") and Organisational Impact ("O") is analysed. Finally the correlation analysis between the Organisational, Business Process and Environment Variables is shown ("O/B/E").

\section{1) Business process and IS environment correlations}

A number of business process variables correlated with variables from the IS Environment.

B1 - "Business reports automatically generated by the system at the appropriate times", correlated with F4 - Use data warehouse application(s). (Spearman R of 0.520). Thus the use of BI applications has a positive correlation with effective business reports.

B4 - "Integrated business processes" correlated with variable F6 - "Defined set of standards to assist making decisions with regards the purchase of technology and applications" (Spearman R of 0.547) and B5 - "Efficient business processes" correlated with F2 - "Has formal documentation about information and communication infrastructure (hardware) and application (software) portfolio" (Spearman R of 0.508). Thus a structured approach to ICT investment correlates with improved integration (and automation) of business processes.

F2 - "Has formal documentation about information and communication infrastructure (hardware) and application (software) portfolio" correlated with construct NT - New Technology was introduced in the organisation / is considered to be introduced (Spearman R of 0.606). F2 also correlated with construct MA - maturity of the IT function. Thus organisations with a more mature IT function, have more formal documentation about their ICT systems. This is in line with Orminski (as cited in Jorosi, 2006), stating that the more mature the organisation, the more formal and systematic the planning strategy will be.

\section{2) Business processes and IS capability correlations}

BP-AU - "Increased Business Process Automation" correlated significantly with the following constructs and variables.

- AI-Improved Application/Technical Integration (0.674)

- BP-AG - Business Process Agility (0.536)

- T3-Different hardware components / vendor solutions are compatible (0.529)

- S2-Software applications are well integrated. (0.728)

- D3 Information outputs are relevant for decision making. (0.538)

T6 - "IT system hardware is stable" correlated with B4 "Integrated business processes" (Spearman R of 0.5433), thus increased technical reliability is associated with increased business process integration - in this regard the respondents probably thought about efficiency as well due to the wording of question B4.

From regression analysis it was found that as application integration and compatibility (T2 and T3) increases, so business process automation (BP-AU) increases. Business process automation is predicted by application integration (AI) $(p=0.005)$ (see Table IV).

TABLE IV: REGRESSION FOR DEPENDENT VARIABLE: BP-AU

\begin{tabular}{lcccc}
\hline \hline$R^{2}=.530$ & $b^{*}$ & $b$ & $t(29)$ & $p$-value \\
Adj. $R^{2}=.417$ & & & & \\
\hline$T 2$ & 0.3624 & 0.4514 & 2.5006 & 0.0183 \\
$T 3(\mathrm{rev})$ & 0.4407 & 0.2698 & 3.1025 & 0.0043 \\
\hline \hline$R^{2}=.696$ & $b^{*}$ & $b$ & $t(31)$ & $p$-value \\
Adj. $R^{2}=.485$ & & & & \\
\hline AI & 0.7734 & 0.8550 & 3.0233 & 0.0050 \\
\hline \hline
\end{tabular}

A regression analysis (see Table IV), was done on BP-AG. BP-AG is not significantly influenced by any of the DQ-S, DQ-I, RR, AI, HM constructs, yet application integration (AI) has a slight influence $(p=0.085)$ on the agility with which business processes can be changed. BP-AG also does not correlate significantly with any Technical, Data or Application software constructs or variables, although agility (BP-AG) and automation (BP-AU) are associated as expected (Spearman R of 0.5361). Biggest influence (though not significant) on business agility is a technical infrastructure that is efficiently managed $(T 7, b=0.292)$ and accommodates change $(T 5, b=0.233)$.

$\mathrm{S} 2$ and B1 - "Business reports automatically generated by the system at the appropriate times" (Spearman R of 0.5043) shows a strong correlation between a technically well-functioning application portfolio and usable application functionality - which is not surprising.

D3 - "Information outputs are relevant for decision making" and B3 - "Automate processes / cutting costs" (Spearman R of 0.5099) correlate, thus business process automation results in more relevant (and perhaps more up to date) information being available for decision making.

Construct DQ-I - "Data Quality (Integration)" correlated with construct MA - "Maturity of IT function" (Spearman R of 0.5690), thus there is a correlation between Data Quality (brought about by application/system integration) and maturity of the IT function in the organization. 
Construct C-ICT - "Consideration for ICTs" correlated with construct BPM - "Business Process Modelling" (Spearman R of 0.5290), Business Process Modelling and awareness / consideration of ICT capability are related, which are both signs of a mature IT function.

\section{3) BPM correlations}

The Spearman correlation between question M1 "We use business process modelling (BPM) tools", and question F4 "We use data warehouse applications (BI applications)" is 0.4453 (at $p<0.01$ ). This indicates that organisations using BI also are more likely to use BPM.

However, M1 (use of BPM) did not correlate with any B (Business Process Effectiveness) and $\mathrm{O}$ (Organisational impact) questions. M1 correlated with F1 (0.3319) $(p<0.05)$ indicating that organisations with mature IT employs BPM (typically large organisations, not SMEs).

It was encouraging to see that there is a correlation, although slight at $0.3679(p<0.05)$, between M1 and O9 ("ICT systems helps organisation to adapt quickly to changes in the business environment"). But we found no correlation between M1 and F2 - formal documentation about information and communication infrastructure (hardware) and application (software) portfolio. The overall lack of correlation of the use of BPM with organisational performance can be the result of various factors (Fasbinder, 2007):

- A picture alone cannot represent the dynamic nature of an organisation.

- Keeping a BPM model up to date is a time consuming process.

- A simple BPM tool does not help drive re-use, reduce redundancy, and increase automation; this depends on the skill of the IT personnel and the maturity of IS and business strategy.

\section{4) Organisational correlations}

Customer satisfaction (B6) correlated with better products and services (O4) (Spearman $R=0.5959)$ and the profit margin of the company (O5) (Spearman $R$ correlation of $0.5441)$, satisfied customers apparently result in recurring sales and the opportunity for cross-selling. We analysed these organisational impact constructs for correlations.

a) PS - Product/Service innovation/value

The following correlations with PS stood out (Spearman Rank correlation coefficient significant at $p<.01$ ):

Data Infrastructure influence:

- D5 - Successful integration of data from different information systems (databases). (0.5112)

- DQ-I - Data Quality (Integration) (0.4457) Software Application Portfolio influence:

- S2 - Software applications are well integrated (0.6113)

- AI - Better Application / Technical Integration (0.5398) Technical infrastructure influence:

- T5 - Technical infrastructure enables implementation of new applications / business processes. (0.4645)

Business Process effectiveness influence:

- B3 - Automate processes / cutting costs. (0.5644)

- B2 - Active monitoring of the efficiency (e.g. turnaround times, lead times) of processes in the organization. (0.5187)
- B6 - Business processes are aligned with customer expectations. (0.4698)

- $\quad$ BP-AU (0.5817)

TABLE IV: REGRESSION SUMMARY FOR DEPENDENT VARIABLE: PS

\begin{tabular}{lcccc}
\hline \hline $\begin{array}{l}R^{2}=.464 \\
\text { Adj. } R^{2}=.334\end{array}$ & $b^{*}$ & $b$ & $t(29)$ & $p$-value \\
\hline B6 & 0.4894 & 0.5925 & 2.2610 & 0.0313 \\
\hline \hline $\begin{array}{l}R^{2}=.322 \\
\text { Adj. } R^{2}=.260\end{array}$ & $b^{*}$ & $b$ & $t(33)$ & $p$-value \\
\hline BP-AU & 0.5466 & 0.5713 & 3.0894 & 0.0041 \\
\hline \hline
\end{tabular}

From IS capability perspective: Product and service innovation is strengthened by a high cohesion (integration) between applications, data and hardware.

From Business process perspective: Product/Service innovation and value (PS) is predicted, by Business Process Automation (BP-AU) (highly significant at $p=0.004$ ). Efficient business processes have the biggest influence on Product/Service effectiveness. Automating business processes (B3) correlates with improved Product and or service delivery $(r=0.5644)$.

\section{b) $O-A G-$ Organisational agility}

Relevant correlations with Organisational Agility (O-AG) were identified. The following correlations with O-AG are highlighted (Spearman Rank correlation coefficient significant at $p<.01)$ :

Data Infrastructure influence:

- D3 - Information outputs are relevant for decision making. (0.4785)

- D5 - Successful integration of data from different information systems (databases). (0.4484)

- DQ-I - Data Quality (Integration) (0.4841)

Software Application Portfolio influence:

- S1 - Software portfolio is optimized / does not have redundant functionality. (0.4641)

Technical infrastructure influence:

- T3 - Different hardware components / vendor solutions are compatible. (0.4226)

Business Process effectiveness influence:

- BP-AU (0.5557)

- B2 - Active monitoring of the efficiency (e.g. turnaround and lead times) of business processes. (0.5363)

- B3 - Automate processes / cutting costs. (0.4919)

- $\quad$ B5 - Efficient business processes. (0.4853)

- B6 - Business processes are aligned with customer expectations. (0.4768)

- B1 - Business reports automatically generated by the system at the appropriate times. (0.4404)

Other correlations:

- $\mathrm{CR}-(0.6818)$

The above shows that, from an IS capability perspective, Organisational Agility correlates most with relevant information for decision making. This also ties in with organisational strategy. However, from a business process perspective, a regression test (see Table $\mathrm{V}$ ), on $\mathrm{O}-\mathrm{AG}$ shows that Business Process Automation (B-AU) is the biggest Business Process effectiveness predictor of organisational agility (O-AG). Interesting also, to note the high correlation between organizational agility and cost reduction (CR). 
TABLE V: REGRESSION SUMMARY FOR DEPENDENT VARIABLE: O-AG

\begin{tabular}{lcccc}
\hline \hline $\begin{array}{l}R^{2}=.371 \\
\text { Adj. } R^{2}=.313\end{array}$ & $b^{*}$ & $b$ & $t(33)$ & $p$-value \\
\hline BP-AU & 0.5577 & 0.5848 & 3.2726 & 0.0025 \\
\hline \hline
\end{tabular}

Interestingly the Business Agility construct did not correlate with Organisational Agility. This can perhaps be of the difficulty of measuring "efficiency" and "alignment" asked by questions B5 and B6.

c) CR-Cost reduction

Relevant correlations with Cost Reduction (CR) were identified. The following correlations with $\mathrm{CR}$ are highlighted (Spearman Rank correlation coefficient significant at $p<.01)$ :

Data Infrastructure influence:

- D3 - Information outputs are relevant for decision making. (0.4323)

- D1 - Data stored in integrated database (no data duplication across systems). (0.4243)

- DQ-I - Data Quality (Integration) (0.4851) Software Application Portfolio influence:

- S1 - Software portfolio is optimized / does not have redundant functionality. (0.6125)

- S2 - Software applications are well integrated. (0.5533)

- AI - Improved Application / Technical Integration (0.6066)

- RR - Reduced Redundancy (Applications and Data) (0.5735)

Technical infrastructure influence:

- T3 - Different hardware components / vendor solutions are compatible. (0.5236)

- $\mathrm{T} 2$ - Follows strategy to reduce infrastructure complexity. (0.4210)

Business Process effectiveness influence:

- B2 - Active monitoring of the efficiency (e.g. turnaround times, lead times) of processes in the organization (0.6460)

- BP-AU - Increased Business Process Automation (0.5813)

- C-ICT - Consideration for ICTs (0.4515)

TABLE VI: REGRESSION SUMMARY FOR DEPENDENT VARIABLE: CR

\begin{tabular}{lcccc}
\hline \hline $\begin{array}{l}R^{2}=.435 \\
\text { Adj. } R^{2}=.299\end{array}$ & $b^{*}$ & $b$ & $t(29)$ & $p$-value \\
\hline $\mathrm{B} 2$ & 0.6215 & 0.4569 & 2.3343 & 0.2671 \\
\hline \hline
\end{tabular}

From IS capability perspective, Organisational Cost Reduction I related to doing more with less with regards to the technical and software portfolio. If the technical and hardware portfolio is optimized, redundancies in technology and applications are reduced and the cost of maintaining IT comes down.

From business process perspective, Cost Reduction is influenced the most by a focus on the efficiency of processes in the organisation (see Table VI).

\section{d) $R G-$ Revenue growth}

Relevant correlations with Revenue Growth (RG) were identified. The following correlations with RG are highlighted (Spearman Rank correlation coefficient significant at $p<.01)$ :
Data Infrastructure influence:

- D6 - Awareness of POPI act (Protection of Personal Information). (0.5465)

- D3 - Information outputs are relevant for decision making. (0.4775)

Software Application Portfolio influence:

- S2 - Software applications are well integrated. (0.4701)

- AI - Improved Application / Technical Integration (0.4425)

Technical infrastructure influence:

- No correlation.

Business Process effectiveness influence:

- B3 - Automate processes / cutting costs.(0.5620)

- BP-AG - Business Process Agility(0.5038)

- C-ICT - Consideration for ICTs (0.4995)

TABLE VII: REGRESSION SUMMARY FOR DEPENDENT VARIABLE: RG

\begin{tabular}{lcccc}
\hline \hline $\begin{array}{l}\mathrm{R}^{2}=.492 \\
\text { Adj. } \mathrm{R}^{2}=.369\end{array}$ & $\mathrm{~b}^{*}$ & $\mathrm{~b}$ & $\mathrm{t}(29)$ & $\mathrm{p}$-value \\
\hline $\mathrm{B} 3$ & 0.3976 & 0.4077 & 2.1392 & 0.0409 \\
\hline \hline
\end{tabular}

From IS capability perspective, improved decision making and integration of applications correlate with Revenue Growth.

From Business process perspective, automating business processes (with a focus of making it more efficient) (B3, see Tab VII), and considering the role of ICTs in business strategy correlate with Revenue growth.

e) VI-Vendor influence

Relevant correlations with Vendor Influence (VI) were identified. The following correlations with VI are highlighted (Spearman Rank correlation coefficient significant at $\mathrm{p}<.01$ ): Data Infrastructure influence:

- D2 - Data is successfully consolidated, shared and compared across systems. (-0.4679)

Technical infrastructure influence:

- $\quad$ T6 - IT system hardware is stable. (-0.4283)

From IS capability perspective, a negative correlation exists between the influence from vendors (VI) and stability of ICT systems (D2; T6), highlighting the difficulty of integrating new ICT solutions.

\section{E. Comparison of Large and Small Organisations}

The differences between small and large organisations in how they utilize their ICTs, and how they differ in their approach to ICTs were analysed. On the whole, there were remarkably few differences between SMEs $(n=20)$ and larger organisations $(n=17)$. In a number of cases, there was a suggestive but not statistically significant difference so the relatively small number of respondents may have masked some of the other differences.

Statistically significant differences were (see Table VIII):

- SMEs have lower levels of standardisation and technical complexity.

- SMEs have less active monitoring of efficiency of their business processes (B2) than larger organisations.

- SMEs make less use of Process Modelling software (BPM, M1, M2).

- SMEs are less likely to have business warehouse applications (F4) and clear guidelines for making ICT 
investment decisions (F6), even though there is no statistical difference with the purchase of ICTs (F8, F9).

- SMEs are less likely to have an in-house IT department (F1)

Interestingly, there was no statistically significant difference in their ICT spent. SMEs also did not depend more on their vendor's skills.

\begin{tabular}{lcccc}
\multicolumn{5}{l}{ TABLE VIII: SIGNIFCANT DIFFERENCES BETWEEN SMES \& LARGE ORG } \\
\hline \hline T-tests & Mean SME & $\begin{array}{l}\text { Mean } \\
\text { Large }\end{array}$ & $t$ & $p$-value \\
\hline T3 & 2.700 & 3.765 & -2.328 & 0.0258 \\
B2 & 3.050 & 3.882 & -2.284 & 0.0286 \\
BPM & 2.958 & 3.686 & -2.896 & 0.0065 \\
M1 & 2.150 & 3.235 & -2.709 & 0.0104 \\
M2 & 3.368 & 4.118 & -2.557 & 0.0152 \\
F4 & 2.500 & 3.941 & -3.631 & 0.0009 \\
F6 & 3.450 & 4.118 & -2.093 & 0.0436 \\
F1 & 3.300 & 4.556 & -2.762 & 0.0091 \\
\hline \hline
\end{tabular}

\section{SUMMARY OF FINDINGS}

The overall theme that emerged was that the majority of organisations surveyed, invested in new technology (hardware/software) in the last 12 months, and that it applied to both SMEs and large organisations equally. But cost was indicated as a major concern, with 26 of 37 respondents indicating that they (mostly) agree that costs constrain their ICT investment (F7). ICTs are considered an important component of the business strategy (E2). Given our sample was chosen to consist of information technology intensive industries, this is not surprising.

Efficient business processes were shown to depend on an integrated ICT infrastructure. There is awareness of the value ICTs present to the organisation, although it is not clear from the survey if they value ICTs for its business strategy opportunities, or purely only from a support role perspective. High correlation was seen between cutting costs and business process automation, which seems to indicate that organisations mostly value ICTs for their support role in the business operations. Business process automation in turn correlated with improved customer service, and perceived competitive advantage. Customer Satisfaction is an important consideration in the organisations surveyed since most are in service industries.

Interesting was the correlation between Organisational Agility (O-AG) and Cost Reduction (CR). A high correlation between Cost Reduction (CR) and improved application integration (AI) was seen. Business Process Modelling did not directly correlate with organisational performance, which emphasises that the ability and expertise of IT staff is very important to unlocking value from an organisation's ICTs. The same sentiment was seen with the value that outside vendors add to the organisation; their lack of expertise was highlighted as an issue.

\section{CONCLUSION}

This study surveyed small and large organisations in South
Africa, to determine what the impact (and value) of the IS architecture and maturity of the IS function is on the business processes and the organisation as a whole. We also compared larger versus smaller organisations as well as informative-intensive versus non information-intensive organisations. A model proposed by Espinosa et al. (2011) was used as the theoretical framework. This model was operationalized with a survey instrument of our own desing. Empirical data led us to re-conceptualize some of the constructs which led to a new and empirically grounded model (Fig.2) which should be useful to other researchers.

Our key findings were that there is a strong empirical basis for many of the claimed benefits of EA. In particular, EA seems to facilitate business process automation, more so (in our sample) than business agilty. However, EA has real organisational impacts, enabling especially long term cost reduction and enterprise agility. Also, although the higher importance and impact of EA and ICTs in information-intensive organisations was confirmed, surprisingly few significant differences were found between large and small organisations. These findings lend empirical weight to EA benefit claims made by EA practitioners.

Future research will hopefully validate and refine both our new model as well as our research instrument further. Additional empirical evidence to support the claimed EA benefits on business processes and organisational impacts will be useful for practitioners and organisations looking to adopt EA. Ideally, this will be done with larger sample sizes, in which case additional differences between large and small companies may be discovered.

\section{ACKNOWLEDGMENT}

Financial support for this research was received from the National Research Foundation.

\section{REFERENCES}

[1] R. Ismail, R. Jeffery, and J. P. Van Belle, "Using ICT as a value adding tool in South African SMEs," Journal of African Research in Business and Technology, 2011.

[2] J. A. Espinosa, W. F. Boh, and W. DeLone, "The organizational impact of enterprise architecture: a research framework," in Proc. 44th Hawaii International Conference on System Sciences, 2011, pp. 1-10.

[3] R. Malan and D. Bredemeyer. (2005). Enterprise architecture as strategic differentiator. [Online]. Available: http://www.bredemeyer.com

[4] C. Perks and T. Beveridge, Guide to Enterprise IT Architecture, New York: Springer-Verlag, 2003.

[5] G. Doucet, J. Gøtze, P. Saha, and S. Bernard, "Coherency management: Using enterprise architecture for alignment, agility, and assurance,' Journal of Enterprise Architecture, vol. 4, no. 2, pp. 9-20.

[6] J. W. Ross, "Enterprise architecture: Driving business benefits from IT," MIT Sloan Research, 2006.

[7] P. Veasey, "Use of enterprise architectures in managing strategic change," Business Process Management Journal, vol. 7, no. 5, pp. 420-436.

[8] T. Iyamu, "The factors affecting institutionalization of enterprise architecture in the organization," in Proc. IEEE Conf. Commerce and Enterprise Computing (CEC), 2009, pp. 221-225.

[9] M. Lakhdissi and B. Bounabat, "Toward a novel methodology for IT Strategic Planning," in Proc. 2nd Intl. Conf. on Information Management and Evaluation, 2011, p. 263.

[10] N. Gorla, T. M. Somers, and B. Wong, "Organizational impact of system quality, information quality, and service quality," Journal of Strategic Information Systems, vol. 19, no. 3, pp. 207-228.

[11] M. P. Drennan, "Information intensive industries in metropolitan areas of the United States of America," Environment and Planning A, vol. 21 , no. 12 , pp. 1603-1618. 
Charl Gideon Van Zijl graduated with the B.Sc (Hons) degree in computer science in 1991, and B.Com (Hons) degree in information systems in 2013. $\mathrm{He}$ has a lifelong interest in computers and ways of applying technology. $\mathrm{He}$ is a detail orientated individual who enjoys finding creative ways to solve problems. Currently he is employed as a systems analyst at Santam, a leading short term insurance company in South Africa.

Jean-Paul Van Belle holds a licentiate in economics from the University of Ghent, an MBA from the University of Stellenbosch, and a PhD degree from the University of Cape Town. He been an acadenuc at the University of Cape Town for the past 17 years where he is currently a professor in the Information Systems Department and the director of the Centre for IT and National Development in Africa. He has more than 150 peer-reviewed publications in the last ten years. His main research area is the use of emerging information technologies in a developing contry context. 